\title{
KONFIGURASI MANAJEMEN BANDWIDTH MENGGUNAKAN ROUTER MIKROTIK RB2011UIAS-RM UNTUK MENGONTROL PENGGUNAAN INTERNET DI PT REKAN USAHA MIKRO ANDA TEGAL
}

\author{
Martselane Adias Sabara ${ }^{1}$, Ari Prayogi ${ }^{2}$ \\ Teknik Elektronika Politeknik Harapan Bersama Tegal \\ email: ㅎaradiaz@ymail.com, ariprayogi69@gmail.com²
}

\begin{abstract}
Tujuan dari implementasi Management Bandwidth dengan menggunakan Queue Tree ini untuk memberikan Quality Of Service yang baik bagi seluruh pengguna internet di PT Rekan Usaha Mikro Anda Cabang Tegal. Latar belakang dalam hal ini adalah karena sering terjadi pembagian bandwidth yang tidak merata pada setiap user yang mengakibatkan satu user dapat mengakses internet dengan cepat dan user lain mengakses internet lebih lambat dibandingkan user lainya.

PT Rekan Usaha Mikro Anda adalah perusahaan yang berbasis teknologi dengan misi sosial untuk meningkatkan kualitas hidup masyarakat berpenghasilan rendah agar dapat hidup mapan dan mempunyai daya saing. Berdiri sejak tahun 2009, saat ini PT Rekan Usaha Mikro Anda memiliki 51 cabang yang tersebar di pulau Jawa dan Bali, dan akan terus mengembangkan jaringannya di seluruh wilayah di Indonesia.

PT, Rekan Usaha Mikro Anda merupakan mitra dari PT Aplikasi Karya Anak Bangsa atau yang yang biasa dikenal dengan GOJEK . Perusahaan ini bergerak dalam bidang penjualan dan pengiriman barang-barang elektronik maupun kebutuhan rumah tangga dengan sistem penjualanya berbentuk arisan barang. Dengan menerapkan Management Bandwidth di PT Rekan Usaha Mikro Anda Cabang Tegal menggunakan Queue Tree ini dengan metode Per Connection Queue (PCQ) diharapkan penggunan internet akan lebih terkontrol dan stabil karena setiap user akan mendapatkan akses internet dengan alokasi bandwidth yang merata.
\end{abstract}

Kata Kunci: Bandwidth, Mikrotik, Queue tree, Qualliy Of Service, Per Connection Queue, PCQ, QoS

\section{PENDAHULUAN}

Perkembangan ilmu dan teknologi yang semakin pesat ternyata membawa perubahan dalam segala lapisan masyarakat. Kreativitas manusia semakin berkembang sehingga mendorong diperolehnya temuan - temuan baru dalam teknologi yang dapat dimanfaatkan sebagai sarana peningkatan kesejahteraan manusia. Salah satu produk manusia tersebut adalah internet. Teknologi internet dewasa ini semakin berkembang pesat, salah satu manfaatnya adalah sebagai sarana untuk mengakses informasi dengan cepat.

Internet adalah jaringan jutaan jaringan interkoneksi yang dapat di akses secara global dan dapat di akses publik yang membentuk tulang punggung informasi.

Di jaman yang semakin modern ini internet sudah menjadi suatu kebutuhan pokok bagi kehidupan sehari-hari. Namun untuk melakukan akses internet tidak murah dan mudah. Diperlukan biaya yang cukup mahal dan alat khusus yang dapat menghubungkan laptop dengan sebagai penunjang internet. Dalam perusahaan saat ini sarana internet juga sangat diperlukan. Karena dengan internet dapat memudahkan perusahaan pekerjaan untuk karyawan. Namun mendistribusikan internet dengan baik diperlukan infastruktur dan sistem manajemen jaringan yang baik.
Mikrotik adalah sistem operasi dan perangkat lunak yang dapat digunakan untuk menjadikan komputer menjadi router network yang handal, mencakup berbagai fitur yang dibuat untuk IP Network dan jaringan wireless, cocok digunakan oleh ISP, provider hotspot dan warnet. Mikrotik didesain untuk mudah digunakan untuk keperluan administrasi jaringan komputer, seperti merancang dan membangun sebuah sistem jaringan komputer skala kecil hingga yang kompleks sekalipun. Salah satu fungsi dari Mikrotik yaitu bisa mengontrol akses internet setiap pengguna dengan menggunakan bandwidth manajemen.

Bandwidth (pemakaian jalur data) yang digunakan membutuhkan suatu pengaturan untuk mengontrol kapsitas bandwidth. Program pengaturan kontrol kapasitas akses data didalam jaringan komputer sering disebut dengan shaping bandwidth atau bandwidth management. Didalam Mikrotik OS terdapat fitur Queue untuk memudahkan pengaturan tersebut. Permasalahan bandwidth, adalah permasalahan yang paling sering kita temui dalam teknologi jaringan komputer. Banyaknya jumlah komputer dalam sebuah kantor yang menginginkan terkoneksi ke internet tidak diimbangi dengan ketersediaan bandwidth yang cukup. Minimnya bandwidth yang tersedia, sangat berpengaruh dengan kecepatan akses ke internet. Oleh karena itulah harus ada suatu manajemen bandwidth yang tepat dalam mengoptimalisasi keterbatasan bandwidth tersebut.

\section{TINJAUAN PUSTAKA}

Pada tinjauan pustaka ini membahas penelitian sebelumnya terkait tentang Pembangkit Listrik Tenaga Mikro Hidro (PLTMH) sebagai berikut:

1. Prasetyo Herry Bayu, Troubleshooting Cisco, Penulis ini membahas perancangan pengendali jammer, dilanjutkan pembahasan bagaimana cara mengatasi troubleshooting yang ada di cisco. ${ }^{[1]}$

2. Jose San, Cisco 1800 Series Integrated Services Routers ( Modular) Hardware Installation Guide. Penulis ini membahas tentang bagaimana cara menginstall cisco 1800 series dan modular untuk integrated services. ${ }^{[2]}$

\subsection{Bandwidth}

Bandwidth (lebar pita) adalah luas atau lebar cakupan frekuensi yang digunakan oleh sinyal dalam medium transmisi. Dalam kerangka ini, Bandwidth dapat diartikan sebagai perbedaan antara komponen sinyal frekuensi tinggi dan sinyal frekuensi rendah. frekuensi sinyal diukur dalam satuan Hertz. sinyal suara tipikal mempunyai Bandwidth sekitar $3 \mathrm{kHz}$, analog TV broadcast (TV) mempunyai Bandwidth sekitar 6 MHz. (Dedy Bintang , 2016)

Pengertian Management Bandwidth adalah suatu alat yang dapat digunakan untuk management dan mengoptimalkan berbagai jenis jaringan dengan menerapkan layanan Quality Of Service (QoS) untuk menetapkan tipe-tipe lalulintas jaringan. sedangkan QoS adalah kemampuan untuk 
Dynamic Host Configuration Protocol (DHCP) menggambarkan suatu tingkatan pencapaian didalam suatu system komunikasi data. (Dedy Bintang , 2016)

\subsection{Mikrotik}

MikroTik RouterOS, merupakan sistem operasi Linux base yang diperuntukkan sebagai network router. Dirancang untuk memberikan kemudahan bagi penggunanya, administrasinya bisa dilakukan melalui Windows Application (WinBox). ( Dwi Febrian Hendriyanto ,2009)

Pengertian Mikrotik adalah sebuah sistem operasi router yang digunakan untuk menjalankan dan mengatur segala aktivitas network (jaringan) secara menyeluruh. Mulai dari routing, routing BGP, billing hotspot, management bandwidth, data user dan load balancing. (Nimas,2018)

Mikrotik didesain untuk mudah digunakan dan sangat baik digunakan untuk keperluan administrasi jaringan komputer seperti merancang dan membangun sebuah sistem jaringan komputer skala kecil hingga yang kompleks sekalipun.

\subsection{Winbox}

Winbox adalah sebuah utility yang digunakan untuk meremote sebuah server mikrotik kedalam mode GUI (Graphical User Interface) melalui operating system windows. Kebanyakan teknisi banyak mengkonfigurasi mikrotik OS atau mikrotik routerboard menggunakan winbox dibanding dengan mengkonfigurasi langsung lewat mode CLI (Command Line Interface). Hal ini karena menggunakan winbox dirasa lebih mudah dibanding melalui browser. Dan hasilnya pun juga lebih cepat. (Ahmad Solehudin Romdoni ,2014)

\subsection{Hotspot}

Hotspot adalah istilah untuk suatu area dimana user atau orang apat mengakses jaringan internet, asalkan menggunakan PC, laptop atau perangkat lainnya yang memiliki fitur berupa WiFi (Wireless Fidelity) sehingga bisa mengakses internet tanpa media kabel. (Rifqi Mulyawan, 2019)

Pengertian Hotspot yang lain, Hotspot adalah area dimana seorang client bisa terhubung dengan internet secara wireless (nirkabel atau tanpa kabel) dari PC, Laptop, notebook ataupun gadget seperti Handphone dalam jangkauan radius kurang lebih beberapa ratus meter tergantung dari kekuatan frekuensi atau signalnya.

\subsection{Firewall}

Firewall adalah suatu sistem perangkat lunak yang mengizinkan lalu lintas jaringan yang dianggap aman untuk bisa melaluinya dan mencegah lalu lintas jaringan yang dianggap tidak aman. Umumnya, sebuah tembok api diterapkan dalam sebuah mesin terdedikasi yang berjalan pada pintu gerbang (gateway) antara jaringan lokal dengan jaringan internet. (Adi Catur Pamungkas,2017)

\subsection{NAT (Network Address Translation)}

Network Address Translation atau sering disebut dengan singkatannya, NAT merupakan proses penerjemahan atau perubahan dari satu alamat IP ke alamat IP lainnya. Ada dua macam NAT di Mikrotik, yaitu NAT tujuan atau $d s t$-nat dan NAT asal atau src-nat. Dst-nat digunakan untuk mengubah alamat IP untuk paket yang ditujukan ke jaringan NAT, sedangkan src-nat digunakan untuk mengubah alamat IP paket yang bersumber dari jaringan NAT. (Hermawan, 2019) merupakan service yang memungkinkan perangkat dapat mendistribusikan atau assign IP Address secara otomatis pada host dalam sebuah jaringan. Cara kerjanya, DHCP Server akan memberikan response terhadap request yang dikirimkan oleh DHCP Client. (Citraweb, 2018)

\subsection{IP Address}

IP Address merupakan deretan bilangan biner diantara 32 bit hingga 128 bit yang dipakai sebagai media untuk mengidentifikasi untuk setiap perangkat komputer yang terhubung pada jaringan komputer (intranet atau internet). Bilangan biner 32 bit dipakai untuk setiap IP Address versi IPv4, sedangkan bilangan biner 128 bit digunakan untuk setiap versi IP Address IPv6. (Wikipedia, 2019)

\section{HASIL DAN PEMBAHASAN}

\subsection{Perancangan Sistem}

Perancangan sistem sangat dibutuhkan untuk mendapatkan suatu sistem yang dapat berjalan dengan baik, diantaranya mencakup persiapan sistem, perancangan jaringan, perancangan hardware dan brainware. Untuk membangun sebuah jaringan internet berbasis nirkabel sebagai sarana untuk memenuhi kebutuhan akan jaringan internet dibutuhkan beberapa tahapan yang harus dilakukan, adapun beberapa tahapan yang harus dilakukan yaitu:

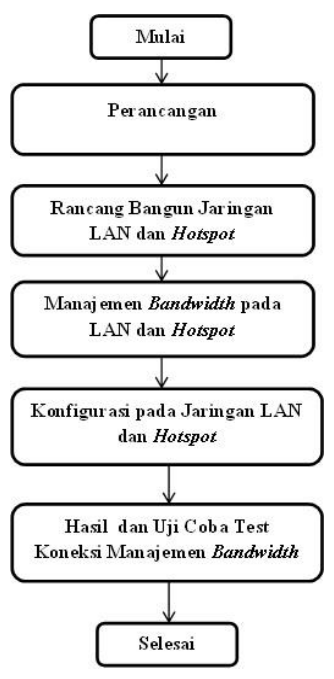

Gambar 1 Diagram Blok Perancangan Sistem

Pada perancangan ini dibutuhkan perangkatperangkat agar dapat membuat konfigurasi manajemen bandwidth di PT Rekan Usaha Mikro Anda Tegal. Perangkat-perangkat tersebut meliputi :

1. Perangkat Keras (Hardware)

Untuk mendukung terlaksananya perancangan sebuah jaringan diperlukan persiapan penerapan sistem yang dirancang, maka sistem ini membutuhkan peralatan sebagai berikut :Dua unit router cisco 1841 series
a. Kabel UTP
b. Mikrotik RB 2011 UiAS-RM
c. Acces Point Tenda N301
d. Tang Crimping
e. Stop Kontak
f. Laptop atau PC

2. Perangkat Lunak (Software) 
Adapun perangkat lunak yang digunakan untuk membuat konfigurasi bandwidth diantaranya :

a. $\quad$ Driver $\mathrm{CH} 340$ untuk kabel $\mathrm{RS} 232$

b. Putty/Hyperterminal/ZOC7

\section{HASIL DAN IMPLEMENTASI PRODUK}

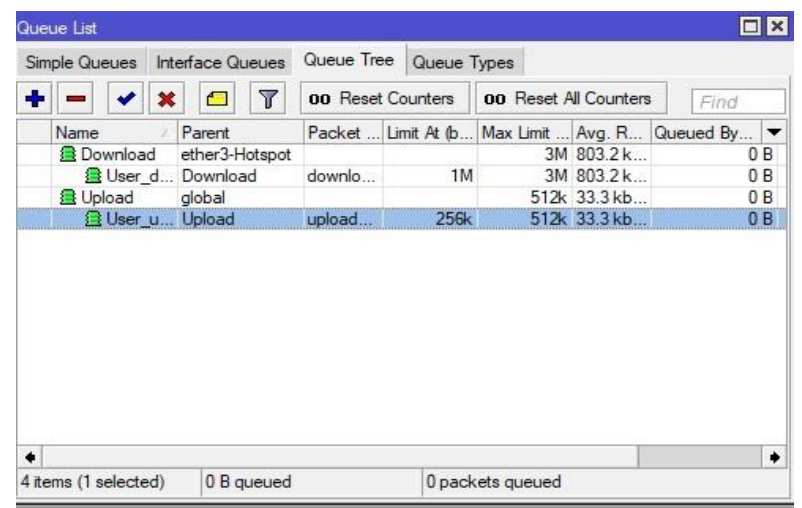

Gambar 2 Tampilan Bandwidth Saat Normal

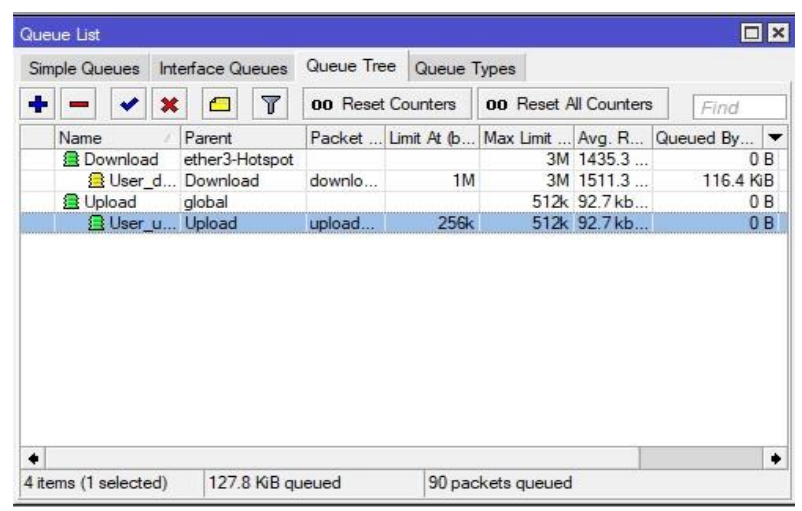

Gambar 3 Tampilan Bandwidth Saat Mendekati Maksimal

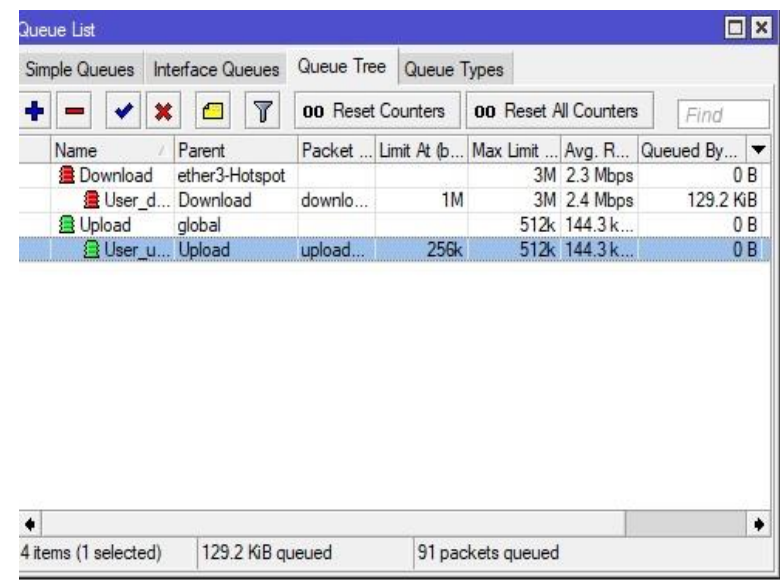

Gambar 3 Tampilan Bandwidth Saat Maksimal

\begin{tabular}{|cccccc|}
\hline & $\mathrm{Mb}$ & $\mathrm{Mb}$ & $\mathrm{Mb}$ & $\mathrm{Mb}$ & $\mathrm{Mb}$ \\
\hline Upload & 0.51 & 0.48 & 0.40 & 0.45 & 0.49 \\
& $\mathrm{Mb}$ & $\mathrm{Mb}$ & $\mathrm{Mb}$ & $\mathrm{Mb}$ & $\mathrm{Mb}$ \\
\end{tabular}

\section{KESIMPULAN}

1. Mikrotik yang telah diimplementasikan mampu memaksimalkan kecepatan internet dengan menggunakan management bandwidth.

2. Management Bandwidth pada komputer berhasil terkoneksi internet dengan lancer, di samping itu penggunaan manajemen bandwidth dengan Quеие Tree lebih komplek dan terperinci.

3. Penggunaan Router Mikrotik di kantor PT Rekan Usaha Mikro Anda sebagai pengontrol internet sangat bermanfaat dengan menggunakan manajemen bandwidth semua pengguna internet di setiap kantor mendapatkan bandwidth yang sama.

Tabel 4.3 Hasil Test Bandwidt

\begin{tabular}{|lccccc|}
\hline Hasil Test & 1 & 2 & 3 & 4 & 5 \\
\hline Download & 2.78 & 2.89 & 2.80 & 2.56 & 2.71 \\
\hline
\end{tabular}




\section{DAFTAR PUSTAKA}

[1] Prasetyo Herry Bayu, 2003-2008. Troubleshooting Cisco.

[2] Jose San, 2003-2008. Cisco 1800 Series Integrated Services Routers ( Modular) Hardware Installation Guide.

[3] Gin-Gin Yugianto, Oscar Rachman. 2012. Router Teknologi Konsep, Konfigurasi dan Troubleshooting. INFORMATIKA Bandung.

[4] Handriyanto, Dwi Febrian.2009. Kajian Penggunnaan Mikrotik RouterOS Sebagai Router Pada Jaringan Komputer. Jurnal Universitas Sriwijaya

[5] Herlambang, Moch Linto, Catur L, Aziz. 2008. Panduan menguasai Router Masa Depan Mengggunakan Mikrotik RouterOS. ANDI Publisher: Yogyakarta.

[6] Iwan Sofana. 2013. Membangun Jaringan Komputer. INFORMATIKA Bandung. 